University of Windsor

Scholarship at UWindsor

OSSA Conference Archive

OSSA 3

May 15th, 9:00 AM - May 17th, 5:00 PM

\title{
Are economists rational or just different?
}

\author{
Tammy James \\ Brock University \\ Lewis Saroka \\ Brock University \\ John Benjafield \\ Brock University
}

Follow this and additional works at: https://scholar.uwindsor.ca/ossaarchive

Part of the Philosophy Commons

James, Tammy; Saroka, Lewis; and Benjafield, John, "Are economists rational or just different?" (1999). OSSA Conference Archive. 29.

https://scholar.uwindsor.ca/ossaarchive/OSSA3/papersandcommentaries/29

This Paper is brought to you for free and open access by the Conferences and Conference Proceedings at Scholarship at UWindsor. It has been accepted for inclusion in OSSA Conference Archive by an authorized conference organizer of Scholarship at UWindsor. For more information, please contact scholarship@uwindsor.ca. 
Title: Are economists rational or just different?

Author: JohnBenjafield/Tammy James/Lewis Soroka

Response to this paper by: Robert Pinto

(c) 2000 John Benjafield, Tammy James \& Lewis Soroka

\section{INTRODUCTION}

There is a growing literature suggesting that economists are more likely than others to act self-interestedly, and less likely to behave cooperatively. For example, Carter \& Irons (1991) compared the behavior of economics and noneconomics undergraduates in a simple ultimatum bargaining game. This is a two-person game in which one person (the proposer) suggests a division of $\$ 10$ between him/herself and a second person (the Responder). Carter \& Irons found that economics students proposed smaller amounts to the responder than did non-economics students. In a follow-up study, Frank, Gilovich and Regan (1993) compared the behavior of economics and non-economics undergraduates in a prisoner's dilemma game. In this game, acting selfinterestedly may lead to a higher monetary payoff or to a lower reward than would be the case if both players cooperate. In their experiment, Frank, Gilovich \& Regan found that economics students were far more likely to behave self-interestedly (and uncooperatively) than were non-economics majors.

Results such as these have been interpreted as illustrating the way in which a particular model of rationality is inculcated in economics programs. Introductory microeconomics begins with the assumption that individuals seek to maximize their "satisfaction", or "welfare". Similarly, firms act so as to maximize their profits. These are presented as positive, rather than normative, statements that are helpful in understanding economic behavior. Furthermore, the existence of competitive markets, Adam Smith's "invisible hand", ensures that these self-interested behaviours maximize the economic well-being of society. While this simple model is frequently modified in more advanced courses, "from the perspective of many economists, motives other than selfinterest are peripheral to the main thrust of human endeavour, and we indulge them at our peril" (Frank, Gilovich \& Regan, 1993: 159).

Acceptance of this economics perspective, and the higher level of self-interest apparently shown by economics students, does not answer the following question posed by some researchers: Does economics teach self-interested behaviour, or does it attract students who are already predisposed to such behaviour? Researchers have asked, for example, "whether exposure to the self-interest model commonly used in economics alters the extent to which people behave in self-interested ways" (Frank, Gilovich \& Regan, 1993: 159). There is, as yet, no consensus on the answer to this question.

In a broader context, Frank \& Cook (1995) have argued that the competitive values promoted by at least some economists may have led to a cultural preoccupation with a "winner take all" strategy. Using the contemporary United 
States as the primary example, Frank \& Cook (1995) show how the growing inequality between rich and poor may be partially the result of the widespread acceptance of the view that competition is rational and that sharing is for fools. Widespread exposure to the self-interest model may lead many or even most members of an entire culture to "reach a point where suddenly things seem to fall into place and one no longer feels lost and overwhelmed by what is going on ... [O]ne finally sees how it all fits together" (Pinto, 1998, p. 4). The "winner take all" model may be just such a coherent frame of reference that enables individuals to justify selfish behavior as rational.

Of course, one must not exaggerate the extent to which the self-interest model dominates public discourse. Other disciplines, as well as some economists, appear to promote values that are sharply at variance with the self-interest model. Take psychology, for instance, in which individual differences in "social value orientation" have long been the subject of investigation (e.g., De Dreu \& Boles, 1998). Social value orientation is a dimension anchored by those who have an extremely competitive, winner take-all, individualistic orientation and those who have an extremely cooperative, share-and-share-alike, prosocial orientation. The former endorse statements such as "your loss is my gain," while the latter endorse statements such as "do unto others as you would have them do unto you." Even some economists have observed that, in certain contexts, a prosocial orientation may be more appropriate than a competitive orientation. "In an ever more interdependent world, social cooperation has become increasingly important," and perhaps economics education should stress "a broader view of human motivation" than it may at present (Frank, Gilovich \& Regan, 1993, p. 170-171).

We believed that the issues raised by these studies are worth examining in a Canadian context. Our first goal was to replicate and extend the Carter \& Irons (1991) and the Frank, Gilovich \& Regan (1993) studies. We wanted to involve participants from as many undergraduate programs as possible, so as to be able to detect any specific differences between students taking different majors. We hoped that such replications could be a productive source of discussion about the educational values that are appropriate in the 'new world order' (or disorder, as some would have it).

We were also interested in whether or not there would be differences between our results with Canadian participants and those previously found with American participants. These two societies, while similar in many respects, are very different in other respects. Both Canadian society and the governments it typically elects are usually considered to be politically to the left of U.S. society and its governments. The social welfare system is more extensive in Canada, and the government plays a more extensive role in the economy. Due in part to these environmental differences, Canadian participants may respond differently than their American counterparts.

A word of caution is in order concerning what follows. This is very much a work in progress, and our results are only tentative. We hope to be able to provide a 
much more extensive analysis when our study is completed.

\section{REPLICATION AND EXTENSION OF CARTER \& IRONS (1991)}

There were a total of 28 participants who were given $\$ 2$ for participating, and who split $\$ 10$ in each 2-person game. Participants were randomly assigned to a two person simple ultimatum bargaining game. Before participating, the logic of ultimatum bargaining games was thoroughly explained to each participant. In this game, one person (the Proposer) suggested a division of $\$ 10$ between him/herself and a second person (the Responder). If the Responder accepted the offer, then the $\$ 10$ was divided accordingly. If the responder rejected the proposal, then both participants got no more than the $\$ 2$ for participating. The role of proposer and responder were determined by a coin toss.

Carter \& Irons (1991) did not actually carry out the game just described.

Rather, they had their participants, who were undergraduates at a Massachusetts university, imagine what they would propose and what they would accept. We also did this with 20 of our 28 participants, after they had completed the real game.

In the real games, a 5-5 split was proposed in all but two of 14 cases. The two exceptions were a 7-3 and a 6-4 proposal, and only the latter led to a rejection of the proposal. For the imaginary games, the mean amount that participants proposed for themselves was $5.2(\mathrm{SD}=1.4)$. This is the amount kept. The corresponding value when playing the respondent role was $3.6(\mathrm{SD}=1.4)$. This is the amount acceptable. Thus on average, people said that they would propose more for the respondent (4.8) than they would actually accept if they were the respondent.

While we do not yet have enough data to make meaningful comparisons between disciplines within our sample, we can compare our overall results with those from the Carter \& Irons (1991) study, as shown in the figure below. Notice that the amount kept for the Canadian sample is lower than the corresponding amount for the American sample $(t=5.82, d f=18, p<.001)$. Moreover, Canadians have a higher amount acceptable than do the Americans $(t=4.56, d f=19, p<.001)$. Both differences are statistically significant, and serve to reinforce one stereotype of Canadian/American differences. Canadians appear to conform less to the "winner take all" stereotype. Canadians appear not only to want to share the proceeds more equitably, but also to be unwilling to accept as little as Americans when they are on the receiving end. However these data should be interpreted cautiously. Notice that in our real games, the difference between the amount kept and the amount accepted is even smaller than in the imaginary games. We do not have the corresponding data for Carter \& Irons (1991) American participants. It may be that in real games, the American participants would have behaved in a less polarized manner, and this could have influenced their subsequent imaginary games. 


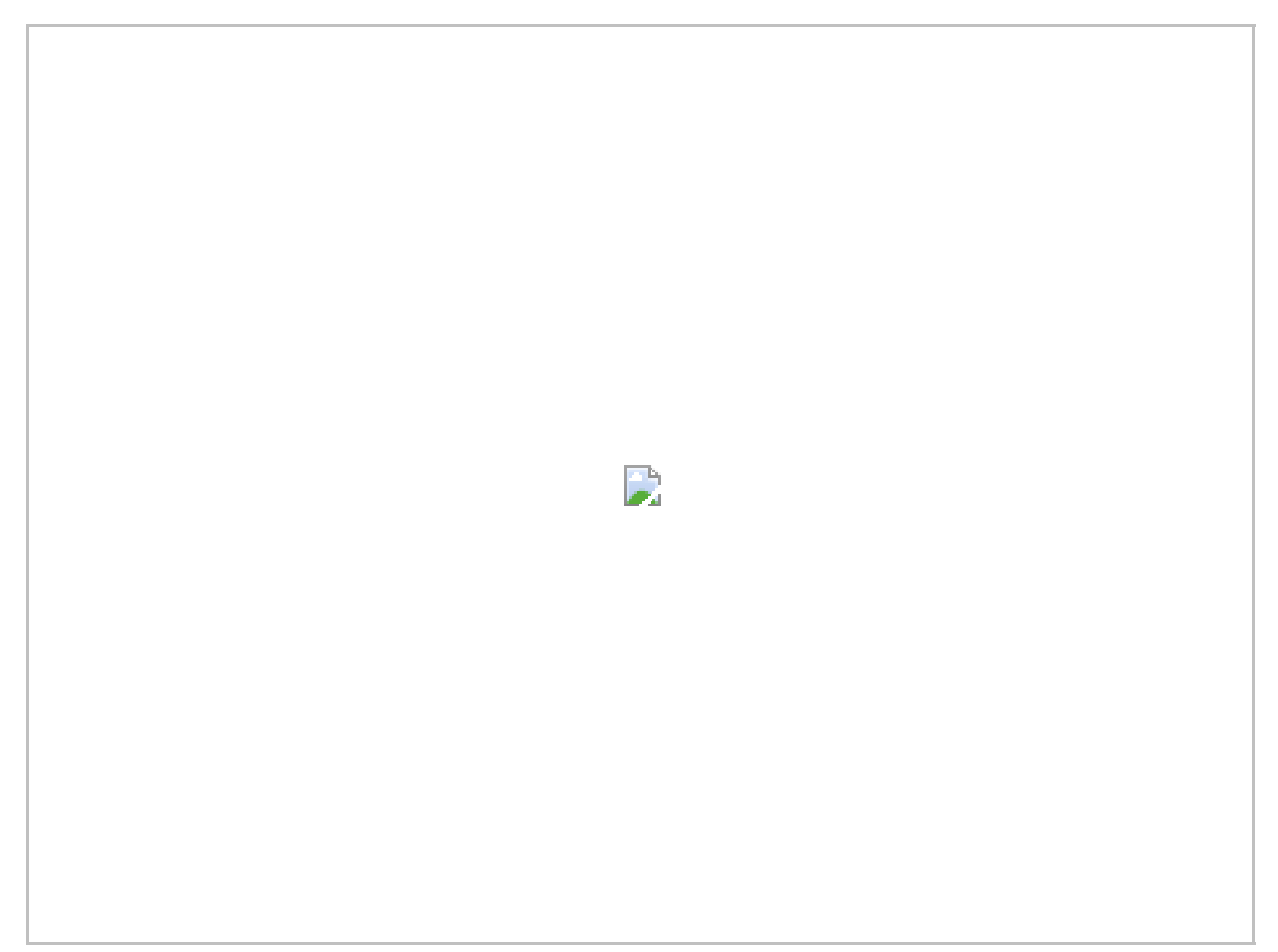

\section{REPLICATION AND EXTENSION OF FRANK, GILOVICH \& REGAN} (1993)

Our second experiment replicated the Frank, Gilovich and Regan (1993) study referred to above. There were 33 participants, each of whom were paid $\$ 2$ for participating and who participated in groups of 3 . Each group member played 2 prisoner's dilemma games, one against each other group member. Before playing, the logic of prisoner's dilemma games was thoroughly explained to each participant. In this game, acting self-interestedly may lead to a higher monetary payoff, or to a lower reward than would be the case if both players cooperate. The payoff matrix (in dollars) for both players is given below.

\begin{tabular}{|c|c|c|c|}
\hline & & \multicolumn{2}{|c|}{ Player X } \\
\hline & & Cooperate & Defect \\
\hline \multirow{2}{*}{ Player Y } & Cooperate & $\begin{array}{l}2 \text { for } X \\
2 \text { for } Y\end{array}$ & $\begin{array}{l}3 \text { for } X \\
0 \text { for } Y\end{array}$ \\
\hline & Defect & $\begin{array}{l}0 \text { for } X \\
3 \text { for } Y\end{array}$ & $\begin{array}{l}1 \text { for } X \\
1 \text { for } Y\end{array}$ \\
\hline
\end{tabular}

After playing both games, participants were given a payoff that was determined by the outcome of their games and by a random number that increased or decreased their payoff such that they were not able to determine with certainty the behavior of their opponents. This "random" factor was explained to participants before the games began. Thus participants received $\$ 2$ plus whatever amount resulted from their games plus or minus a random 
number.

We grouped our participants by discipline as follows. Eleven psychology and child studies students were placed in one group (PSYC), 17 economics, business and accounting students were placed in a second group (ECON), and 6 students from other disciplines (e.g., fine arts, computer science) were placed in a third group (OTHER). All participants were assigned a score of 1 if they cooperated in a game and a score of 2 if they defected.

An analysis of variance showed that there were group differences in these "defection scores," as shown in the figure below $(F=3.30, \mathrm{df}=2,28, p=.05)$. If one considers only the psychology and economics groups, the difference is consistent with the results of Frank, Gilovich \& Regan (1993): Economics students defect more often than psychology students. However, when one adds in the third group, the results are less clear cut. While the psychology students defect less than the other two groups, there is no reliable difference between the latter. Frank, Gilovich \& Regan (1993) only compared economics students with "others," and did not specify the majors of the comparison group. Our results suggest that economics majors may well defect more than some students, such as psychology majors. However, it may be more accurate to put it this way: Psychology students defect less (are more cooperative) than others, including economics majors.

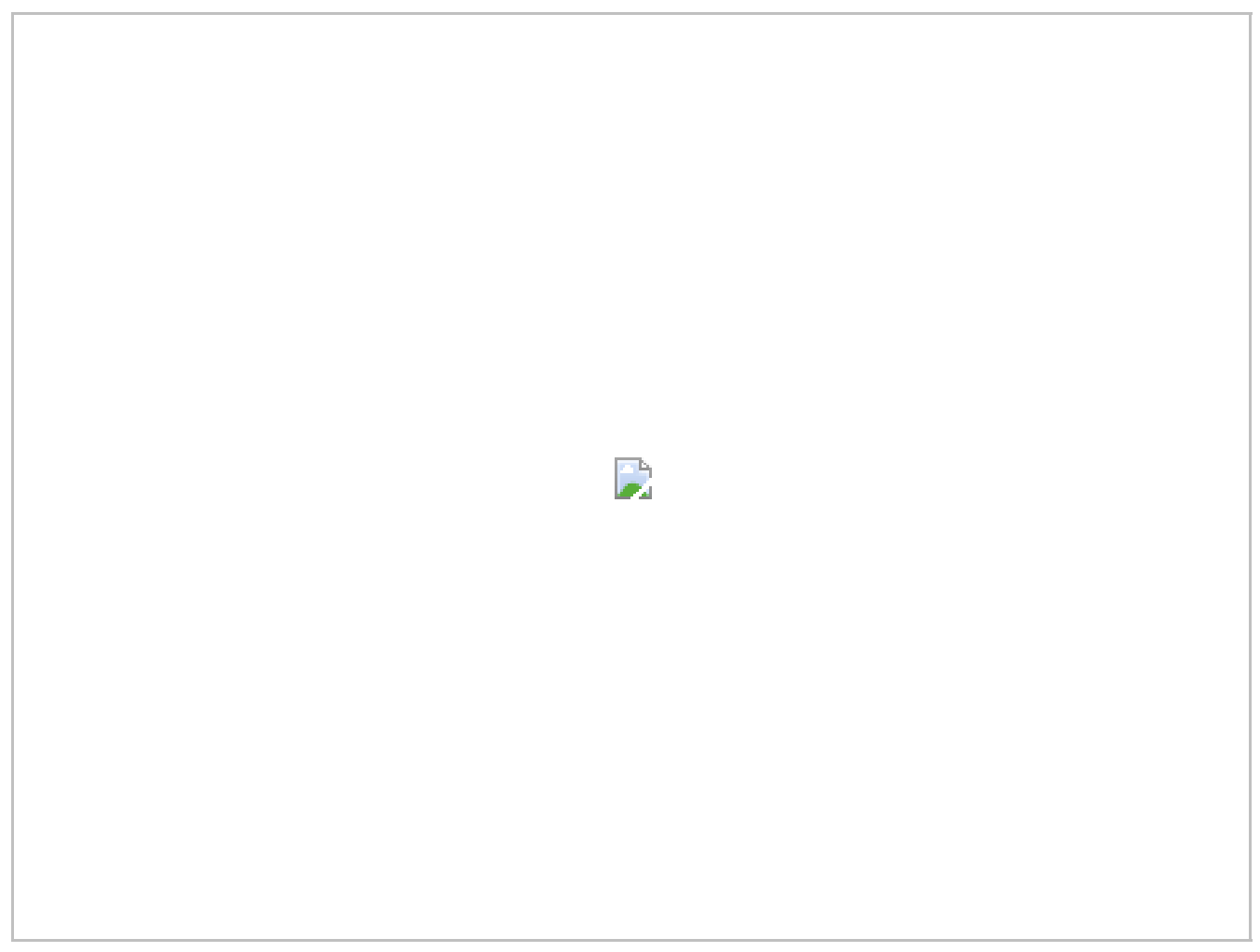

Our results are even more complicated because of an interaction between major and gender $(F=4.14, d f=1,28, p=.05)$. The shape of this interaction is shown in the figure below. Notice that women have identical defection scores in both the psychology and economics groups. Unfortunately, we have as yet no female representatives of the "other" group, a deficiency we intend to remedy in due course. In our current data, the real effect of major is for men. 
Men who are in psychology have the lowest defection score (i.e., are more likely to cooperate). It is these men who are the most "different" in our current sample. In answer to the question posed by our title, economists may or may not be rational, but it is male psychologists who are different.

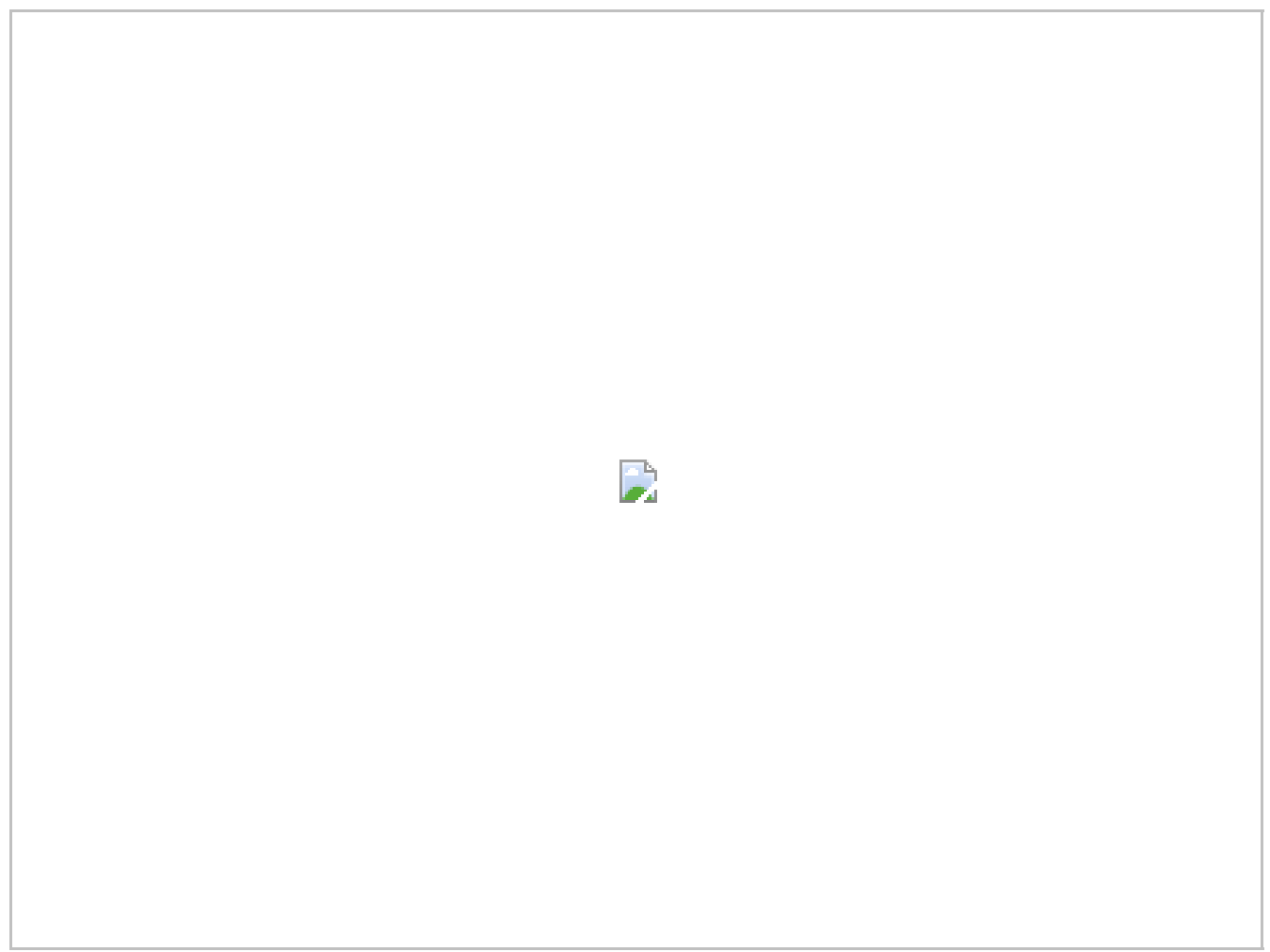

Others (e.g., Frank, Gilovich \& Regan, 1993, p. 164) have observed that the individualistic values promoted by the self-interest model of economics may also be more characteristic of men, while women may be more attracted to prosocial disciplines like psychology. However, when one examines this distinction in more detail, it becomes clear that, like all stereotypes, it obscures the uniqueness of particular cases. Men who choose to study psychology, and women who choose to study economics, may prove to be interesting groups to study further.

One final result may also be worth exploring further. On their response forms, participants first indicated whether they would cooperate or defect in one game with one of the other participants, and then whether they would cooperate or defect in the game with the other participant. Let us call these "Game 1" and "Game 2" respectively. Frank, Gilovich \& Regan (1993) did not examine this variable in their analyses, and so we do not know whether or not the following effect existed in their data. In our data, it turns out that there is an interaction between gender and game $(F=19.26, d f=1,28, p<.001)$, which is illustrated in the figure below. Notice that in Game 1 men and women behave in a way that is consistent with their current stereotype. Women defect less (cooperate more) and men defect more (cooperate less). However, this tendency reverses itself in Game 2. It is as if once someone has decided to defect (or cooperate) in Game 1, then it becomes OK to cooperate (or defect) in game 2. 


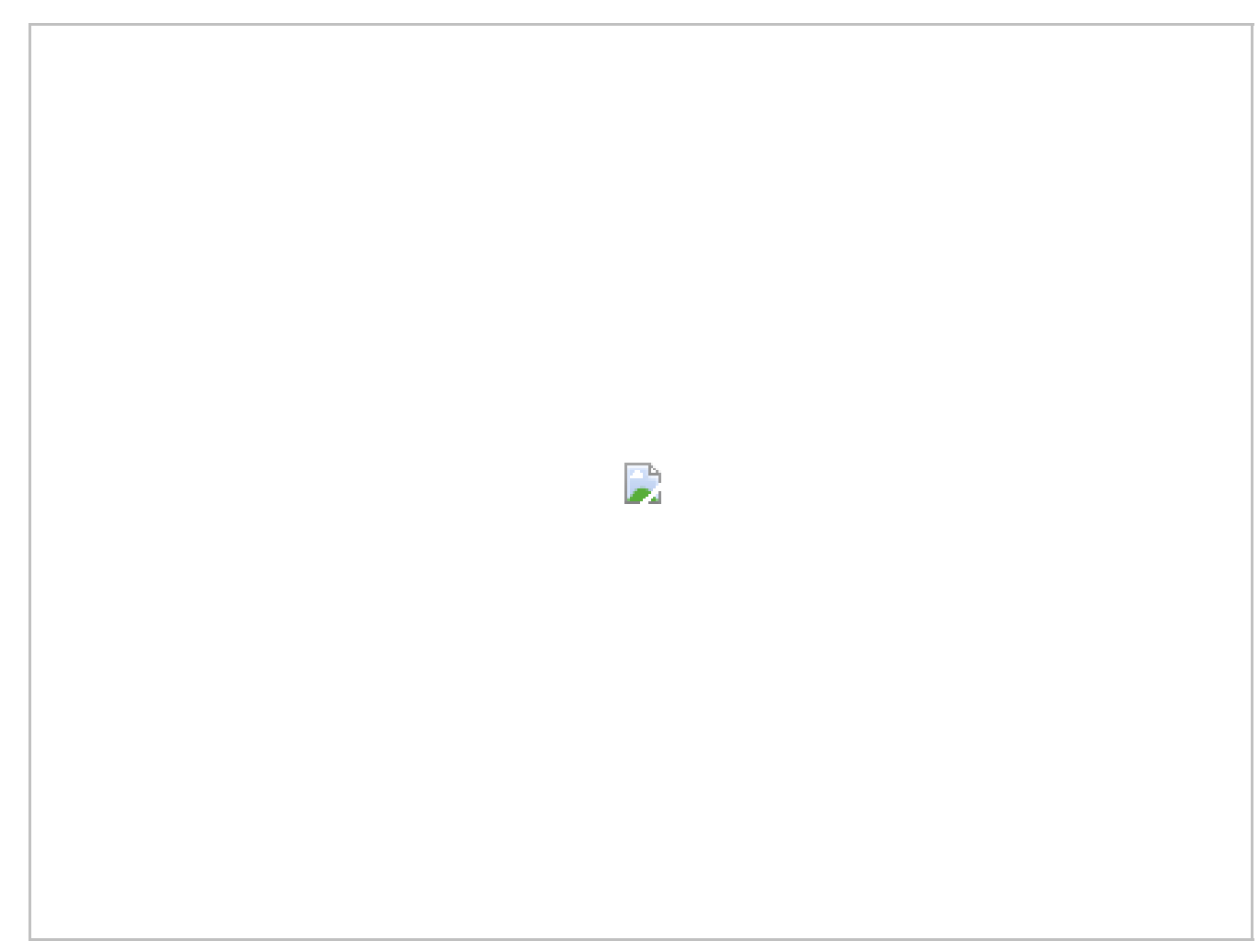

While our results admittedly require replication, it is an irresistible temptation to speculate upon them nonetheless. Psychologists such as Gergen (1991) have suggested that the postmodern self should not be seen as a unitary entity, but rather as a multiplicity of "selves." In the context of our study, perhaps it is unwise to see men and women, or economists and psychologists, as either cooperative or competitive. Rather, it may be more accurate to see each person as both cooperative and competitive. No doubt one part of oneself may have the upper hand on most occasions, but that does not mean that the other parts of oneself never find their voice. The men in our study tended to give voice to the competitive part of themselves in the first instance, but, having done so, allowed their cooperative self the opportunity to express itself. The reverse scenario was enacted by the women in our study.

\section{CONCLUSION}

No doubt it is important to know with whom you are dealing, whether it be economist, psychologist, or other. In general, the psychologist will tend to be more cooperative, and the economist more competitive. However, it may be equally important to know when you are dealing with them. If it is a man, and he has just defeated the competition, then he may be quite happy to cooperate with you. If it is a woman, and she has just reached a cooperative accommodation with another, then it may be a bad time to try to strike bargain. A person's behavior is contextually determined, and relying on stereotypes to make decisions is not a rational procedure.

At the end of the day, our study does not really reinforce previous studies that have suggested that economics education is too narrowly focused on the selfinterest model. Perhaps it is, but the economics students in our sample are not 
necessarily more selfish than other groups. Our studies have examined group differences in more detail than have previous studies, and found as a result that there is no simple story to tell about either economists or psychologists. In this respect, we are reminded of the philosopher John Wisdom (1965: 138), who once told the story of a (perhaps apocryphal) lion keeper at the Dublin Zoo who was renowned for his success at keeping lions healthy under any and all circumstances. He obviously had a deep understanding of lions. At the end of a long and successful career he was asked to divulge the secret of his success. He said that the most important thing was to realize that every lion is different. Thus, a deep understanding of the members of one category (e.g., lions, economists or psychologists) does not mean that you know the same thing about all of them. The beginning of wisdom for educators may be the realization that, like lions, all economics students are different, as are all psychology students, or, for that matter, all the members of any category.

\section{References}

Carter, J.R., \& Irons, M.D. (1991). Journal of Economic Perspectives, 5, 171177.

De Dreu, C.K.W., \& Boles, T.L. (1998). Share and share alike or winner take all?: The influence of social value orientation upon choice and recall of negotiation heuristics. Organizational Behavior and Human Decision Processes, 76, 253-276.

Frank, R.H., \& Cook, P.J. (1995). The winner-take-all society. New York: Penguin.

Frank, R.H., Gilovich, T., \& Regan, D.T. (1993). Journal of Economic Perspectives, 7, 159-171.

Gergen, K. (1991). The saturated self: Dilemmas of identity in contemporary life. New York: Basic Books.

Pinto, R.C. (1998). Logic, coherence and psychology [CD-ROM]. In H.V. Hansen, C.W. Tindale \& A.V. Colman (Eds.), Argumentation and rhetoric. St. Catharines, ON: Ontario Society for the Study of Argumentation.

Wisdom, J. (1965). Paradox and discovery. Oxford: Blackwell. 